\title{
Cooperative Storage Warehouses
}

\author{
BY HELEN JOANNE HARRAR
}

COOPERATIVE STORAGE WAREHOUSES have been suggested as a possible means by which large libraries may, with minimal expenditures, retain and even acquire infrequently used but potentially valuable research material. Three types of this facility exist in the United States today.

The first, exemplified by the New England Deposit Library (NEDL), is a central storage warehouse owned and operated by several participating libraries. Each member merely rents space in a jointlyowned building, determines how its space is to be used, and maintains its own collections. The second type, illustrated by the Hampshire Inter-Library Center (HILC), is a consolidated warehouse owned and supported by a group of cooperating libraries. Each member contributes its little-used serials to the warehouse, which completely integrates the resulting collection. Contributed funds and income from the disposition of duplicates provide for a limited acquisitions program of rarely-consulted serials and expensive sets.

The third type, illustrated by the Midwest Inter-Library Center (MILC), is distinguished from the preceding two types by the scope of its operations and holdings. Materials deposited by members are absorbed into the collections when deposit limitations permit, and duplicates are discarded. Unlike the others, this type has a professional staff which operates library programs approved by the membership and which carries on an acquisitions program designed to supplement members' collections as well as to strengthen library resources in the region. A range of services is provided for the membership and, under certain conditions, for nonmembers as well.
Dr. Harrar is Librarian of Winthrop College, Rock Hill, South Carolina. This article is a summary of a doctoral dissertation accepted by the faculty of the Graduate School of Library Service, Rutgers University, in May 1962. Copies of the dissertation are available from University Microfilms, Ann Arbor, Michigan. This study was supported by the United States Air Force under Contract No. AF 49(638)849, monitored by the Information Services Division, Air Force Office of Scientific Research of the Office of Aerospace Research.

All three types are primarily concerned with little-used materials. The meaning of this term, however, varies from warehouse to warehouse and from member to member, depending upon the exigencies of the moment and the nature of various institutional needs.

The programs of all three have been established upon certain basic assumptions: (1) cooperative storage warehouses provide more economical storage than could be achieved if each member housed the same materials within its own main building and branches; (2) the materials stored receive little use and therefore generate low service costs; (3) cooperative storage warehouses reduce costs even though they necessitate duplication of records and impose additional costs in transporting materials between the warehouses and the requesting libraries; (4) delays in provision of desired material are unimportant as compared with savings in costs; (5) cooperative storage warehouses increase the research resources available to the cooperating libraries.

The purpose of this study is to determine the effectiveness of each of these types of warehouses and to recommend 
optimum measures for storage of littleused materials.

\section{BACKGROUNDS OF THE \\ THREE WAREHOUSES}

The New England Deposit Library program was initiated by Harvard University during the late 1930's. Recalling an earlier storage enterprise proposed by Harvard President Charles W. Eliot, Keyes D. Metcalf suggested that the space dilemma might be solved through an off-campus, low-cost, low-upkeep area in which rarely-used volumes could be stored compactly. To help support the capital investment such a structure would require, Metcalf envisioned a jointly-owned and operated storage warehouse. Incorporation of the NEDL was sanctioned by the state legislature in 1941, and early in 1942 a specially-erected building was opened.

Metcalf hoped that the NEDL would permit elimination of existing and future duplication among members, help to bring about an acquisitions program dividing subject responsibility among them, and allow ready accessibility to all members of the little-used items of any one. ${ }^{1}$ His main purpose, however, was provision of lowcost storage.

Discussion of what was to become the Midwest Inter-Library Center began in the early 1930 's. In a report prepared by Metcalf and John Fall, a jointly-operated storage library was advocated because it would reduce or delay the need for new library buildings, thereby permitting accumulation of cash reserves which could be directed to other needs. It would speed service and eliminate "unjustified wastes" in distances traveled to obtain materials, and allow high-density storage of books at a lower storage cost per volume than would be possible in the conventional library building. Too, it would spur such cooperative efforts as the elimination of unnecessary duplication among deposited

\footnotetext{
${ }^{1}$ Keyes D. Metcalf, "The New England Deposit Library," Library Quarterly, XII (July 1942), 628.
}

materials, as well as cooperative acquisition of little-used items. ${ }^{2}$

In his 1948 survey, Errett W. McDiarmid recommended that the Middle West provide for regional research demands so as to achieve efficient, economical use of present and future resources. The advantages claimed for the cooperative programs he cited were those previously named as well as more intelligent planning of the types of research and graduate programs to be offered. ${ }^{3}$

In 1949 ten research libraries formed the Midwest Inter-Library Corporation, the main purpose of which was the establishment of a center to organize, house, service, and under certain conditions to own, infrequently used research materials. Secondary purposes were the encouragement of coordination of collecting policies in specialized fields and the exploration of possible cooperative bibliographical services.

The Hampshire Inter-Library Center was the result of long-term cooperation among three western Massachusetts colleges, whose librarians had simplified inter-library loan polices, jointly purchased expensive items required by more than one school, and attempted to prevent unnecessary duplication of expensive works through consultation and placement of such items on the campus where most needed. A storage library was seen as the answer to future growth problems, since it might release shelf space in member libraries for current materials, help offset the effects on library budgets of spiraling book and serials costs, and help increase combined research resources. ${ }^{4}$ Incorporated in 1951, HILC was to be devoted primarily to serials. By combining duplicate volumes of journals no long-

\footnotetext{
${ }^{2}$ John Fall and Keyes D. Metcalf, A Proposal for a Middle West Deposit Library (Chicago, 1940). 94p. Mimeo.

${ }^{3}$ Errett W. MeDiarmid, A Midwest Inter-Library Center (Chicago, 1948). 52p. Mimeo.

4 Keyes D. Metealf, The Hampshire Inter-Library Center: A Survey of Its Background and Its Problems With Recommendations for the Future (South Hadley: The Center, 1957). 31p.
} 
er published and of specialized titles not frequently requested, sufficient savings would, hopefully, be realized to permit purchase of additional materials and to "increase the library resources available to each member without requiring each to increase its library expenditures correspondingly."

\section{COMPOSITION OF MEMBERSHIP}

By the end of 1960, the NEDL had eleven members-five colleges and universities, one public library, four special libraries, and the state library-all of which were located in or near metropolitan Boston. MILC then had twenty members, eighteen of which were universities. In contrast to the NEDL, members were located from a few blocks to several hundred miles from the center itself.

At the same time, HILC had four members-the original three colleges plus the state university. The four institutions were geographically isolated from large research collections, but near each other, no member being more than twelve miles from the other three.

\section{OWNERSHIP OF MATERIAL}

Deposits in the NEDL have never, as originally hoped, become its property; neither have the collections been integrated nor duplicates eliminated. MILC has four deposit categories, ranging from transfer of title to the center through provisions for temporary storage by any member library. Reserving the right to reject offered items, MILC generally accepts material if it is not widely held among the membership, has research value within the region, and is little used. While the deposit criteria were broadly interpreted in earlier years, limitations were more rigidly enforced as shelving space diminished. A two-year moratorium on deposits was declared in 1960 so that the backlog of unprocessed deposits might be eliminated. All materials housed in HILC become its property at the time of deposit.
The owning library can, at any time, permanently recall material from the NEDL. Under certain conditions, the depositing library can permanently recall material from MILC, although deposit in categories which permit return is discouraged. Material in HILC is the property of the center; none can be returned to the original owner.

\section{SHELVING of Material}

At the NEDL some members shelve by subject classification and some by the size classification of nine categories devised by Harvard. At MILC a size classification having six classes is used for miscellaneous monographs and serials; other materials are shelved according to self-arranging characteristics. HILC uses a size classification of six categories for the major portion of its holdings.

\section{InPUt of Materials by Members}

At the NEDL each member shelves its own deposits and supports the related costs. The custodian handles only Harvard deposits. A union catalog of holdings was anticipated but has never been created. Aside from an author catalog for Harvard, Radcliffe, and Tufts holdings, and a shelf list of Boston Public library deposits, the NEDL staff has no precise knowledge of what and how much has been deposited. Harvard appears to be the heaviest depositor, but since 1948, when its NEDL space was filled, Harvard has housed additional storage volumes on campus. The Boston Museum of Science, the Massachusetts State Library, and Radcliffe College are the only other current depositors. Their current deposits are infrequent and of no appreciable volume.

MILC members select materials for deposit, within the specified criteria, and pay all costs connected with processing these items for transfer. The center pays all other costs for all deposit categories except temporary storage. Member records dealing with the amount of material de- 
posited are generally informal; MILC's records are precise only for cataloged serials and monographs, which constitute about 10 per cent of the collection. Deposits are less frequent and much smaller than in earlier years. Eight of the twenty members sent varying quantities of material to the center in 1960. According to reports of member librarians, input has dropped for various reasons: early weeding and depositing relieved space needs in member institutions; the 1960 moratorium declared on deposits forcibly slowed the deposits program. The heaviest and most consistent depositor has remained the University of Chicago.

All material placed in HILC, regardless of the mode of acquisition, requires approval of all four members. There is no accurate count of volumes deposited. As of the end of 1960, the University of Massachusetts had deposited least while Mount Holyoke College had deposited most.

Heavy and frequent deposits were made in all three warehouses during the early years of operation. After the initial influx, deposits usually dropped. The heaviest depositors in each instance have been those members closest to each storage facility.

\section{Use of Stored Materials}

The number of items borrowed in any given year from the NEDL is not known, since the facility keeps records only for Harvard, Radcliffe, and the Boston Public library. Records kept by the remaining members, who retrieve their own materials, are informal. Based on the members' estimates, approximately 6350 volumes were borrowed in 1960, of which 62 per cent went to Harvard.

MILC and HILC keep records of all items requested. In 1959-60 MILC lent 1861 volumes; HILC, 1410 . The Chicago area members accounted for almost 50 per cent of the total loans of MILC. The University of Chicago borrowed 23 per cent of the total; John Crerar library, 22 per cent. In the same year HILC provided 28 per cent of its total loans for Mount Holyoke.

For the same period, in-person users of the NEDL numbered 152; of MILC, 198; of HILC, 117. Harvard and Radcliffe together accounted for 67 per cent of on-site NEDL use. The University of Chicago provided 42 per cent of the inperson use at MILC, while Mount Holyoke provided 74 per cent of such use at HILC.

NEDL offers no reference service. MILC verifies bibliographical citations and locates factual information. During 1959-60 the service was performed 166 times, 15 per cent of the total being for the John Crerar library and 13 per cent for the University of Chicago. During this year HILC answered six such questions, of which four were for Smith College.

For all three warehouses, two of the three forms of service (i.e., retrieval, inperson use, and reference service) were most heavily used by the member closest to the center. At the NEDL, Harvard proved the heaviest user of all three services.

\section{Available Space in Storage Buildings}

While less than 5 per cent of the total NEDL stack space remained unused at the end of 1960 , there were no immediate plans to add another stack unit. At the same time, MILC still had available 5 to 10 per cent of its shelf space. The need for another unit was then being discussed only generally. HILC, having moved into new quarters that year, had used only some 35 per cent of its total stack space.

\section{Costs of Storage Buildings, Grounds AND Operations}

The New England Deposit Library was erected in 1942 upon a 50,000 square foot plot donated by Harvard. The final cost of the building, including land- 
Stated cost

Depreciation@2\%

Loss of interest @ 4\%

Real cost
NEDL

$\$ 13,621.19$

$4,300.00$

$8,600.00$

$\$ 26,521.19$
MILC

$\$ 105,504.89$

$7,320.59$

$34,641.18$

$\$ 147,466.66$
HILC

$\$ 19,728.95$

$4,048.37$

$8,096.74$

$\$ 31,874.06$ scaping, shelving, and equipment, was $\$ 223,939$. The Midwest Inter-Library Center was erected in $1950-51$ at a cost of $\$ 866,029.43$ upon a 41,860 square foot plot donated by the University of Chicago. The Hampshire Inter-Library Center has always been housed in space belonging to a member. The estimated cost of the area occupied by the center in its present location, an addition to the University of Massachusetts library, was $\$ 202,418.40$, not including land costs.

To determine the operating costs of each warehouse, the average annual expenditures over 1955-60 were derived from yearly financial statements provided by each center. To the stated averages were added two costs: building depreciation at 2 per cent per year, and loss of interest on money invested in the building at 4 per cent per year.

The stated operating costs, as compared to the real costs, for each warehouse are shown above.

\section{CONCLUSIONS}

From the foregoing the validity of claims for the three cooperative storage warehouses can be determined. A major argument, first cited by President Eliot, has been that warehouses would eliminate the need to hold expensive pieces of land for addition to main library buildings. This no longer holds, because of the development of department libraries which make materials more accessible to the publics most likely to use them. Harvard, with its more than ninety service units, exemplifies the trend. Even with the existence of the NEDL, it has built additional conventional library units on its own campus. Furthermore, to say that construction on inexpensive land is more economical than on expensive land overlooks the fact that land does not depreciate. The purchase of land is merely a conversion of capital from one form to another.

A second argument, that costly enlargements would no longer be necessary, overlooks the fact that expansion of the collection is accompanied by increased staff and readers.

The argument that maintenance of a storage collection would be less costly than maintenance of an "active library" compares dissimilar units. At the NEDL, maintenance of closed stacks, where heat and lighting are reduced, has been proved less expensive than that for an open stack which requires constant upkeep and normal lighting and heating conditions. There is no reason, however, that part of the stacks in any building could not be closed to the public, serviced only as necessary, and maintained with reduced heat and light. Under these circumstances, storage costs would be comparable for the two units.

Frequently overlooked is the fact that bibliographical control is as important for a stored collection as for an open one -perhaps more so, since browsing is automatically eliminated. If stored material is to be controlled, such items must appear in at least the public card catalog or an equivalent. Storage does not, as has been suggested, reduce the size of the catalog. It may, in fact, multiply records for items stored, if those items are to be accessible.

When the NEDL was created, its value 
for compact storage was stressed. Since only four members use size classifications, this value has not been realized. Metcalf stated that one of the major economies offered by the NEDL lay in decreased processing costs. Earlier, when Harvard processed 20-25 per cent of its acquisitions directly for storage, a substantial saving was realized. With the elimination of that procedure some years ago, the additional costs of weeding and deprocessing increased total handling costs. What has not been considered is the fact that inexpensive processing expenditures need not be limited to warehouses. If a library were to use the same partial or simplified cataloging for its on-campus storage collections, cost should be identical with that for off-campus storage. It may be concluded that the economies provided by a storage warehouse could be achieved by any library if the same techniques (i.e., compact storage, inexpensive maintenance, and simplified processing) were used on campus.

The Fall-Metcalf survey indicated that a warehouse would permit accumulation of cash reserves to be used for other purposes and would allow advantages resulting from cooperation. Tax-supported institutions, however, have no reserves since their funds are paid out as needed by the supporting taxing bodies. Too, nonprofit educational institutions do not actually build up cash reserves.

Finally, several MILC members have added storage units on their own campuses, regardless of the center's existence, thereby expending funds which, if the argument were legitimate, could have been diverted to other purposes.

Cooperative acquisition through MILC has resulted, but cooperative cataloging, another possible advantage cited by Fall and Metcalf, has not. Cooperative acquisition, elimination of duplication, and liberalized loan privileges could be carried on by a group of participating institutions without the presence of the stor- age warehouse, as was actually done by the HILC group before the Hampshire Center was established.

Storage in MILC, as in the NEDL, cannot have produced the originally anticipated low cost per volume stored, since the capacity of the center will not, under present conditions, reach the predicted ceiling. Only 10 per cent of the materials are stored by size; much of the remainder is shelved so as to take up at least as much space as would conventional storage.

To date there has been no evidence that MILC has contributed to consideration of types of research programs, to the development or utilization of faculty skills, or to specialization in acquisition and in graduate work, either by individual institutions or by the membership as a whole, as predicted by McDiarmid.

Another argument for the center was that it would reduce the number of staff needed to handle active materials in member libraries, and would decrease the total staff time in the region by reducing duplication of effort. It is obvious, however, that the same results would be achieved by handling material on campus in exactly the same way as in the warehouse.

It was hoped that HILC would be able to save money and still increase total regional resources while promoting institutional cooperation, but there is no evidence that savings have been made. The argument that the center will increase regional resources lacks merit in view of the extensive resources of the Boston area less than one hundred miles away. The members of HILC worked together long before the center's inception, and the schools have maintained other cooperative programs that were independent of HILC.

Storage costs per volume drops as the density of storage increases. It should be possible for individual libraries to convert portions of existing stack space or 
to construct new units employing compact storage and thereby achieve the same economies attributed to the cooperative storage warehouse which uses these same storage methods.

Underlying the concept of cooperative storage warehouses are two important points; one, that such warehouses store little-used but nonetheless valuable research material, and two, that such warehouses promote among libraries cooperation which is highly desirable. It should be reemphasized that the frequency of use does not determine an item's research value. At the same time, caution must be exercised to assure that infrequently-used material of no value is not retained, thereby increasing the costs of handling and maintenance regardless of the system employed.
Secondly, cooperation among institutions is certainly useful, if not essential. Yet cooperative storage facilities are not the only form of cooperation presently available, as arguments favoring these facilities might imply. For example, an important cooperative mechanism which is carried out independently of any warehouse, but which extends the resources of research libraries throughout the nation, is the Farmington Plan.

The three centers discussed here show that cooperation can be achieved in concrete form. The next step is the development of more efficient cooperative methods, which improve regional resources and access to materials without the duplication of processing effort and the extra costs involved in cooperative storage.

\section{Association of Southeastern Research Libraries}

THE Association of Southeastern Research Libraries was convened on Wednesday, November 6, 1963, in the new Auburn University library, Auburn, Alabama. Almost all member libraries were represented, and Chairman W. Porter Kellam (Ga.) presided.

Discussion centered on cooperative activities among the member institutions. Several specific projects were reported upon, including:

1. A joint program for the acquisition of retrospective newspaper files on microfilm, being coordinated by Olive Branch (Tenn.).

2. A project for the cooperative acquisition of retrospective serial desiderata, being administered by David Kaser (Joint University Libraries).

3. A survey of strengths and weaknesses in the holdings of member libraries, being conducted by Stanley West (Florida).

The above projects will continue.

The need was recognized for the standardization of interlibrary loan practices and of photocopying activities as they applied to interlibrary loans in the southeastern region. T. N. McMullin (LSU) will survey existing practices in a first effort to attain some level of uniform activity.

There was discussion of appropriate regional document depositories in the Southeast under the new United States depository law.

Refreshments were served, and, after deciding to meet next in Norfolk, Va. in October 1964, the meeting was adjourned.-D.K. 